\title{
Aloe vera Gel: Effective Therapeutic Agent against Multidrug-Resistant Pseudomonas aeruginosa Isolates Recovered from Burn Wound Infections
}

\author{
Mehdi Goudarzi, ${ }^{1}$ Maryam Fazeli, ${ }^{2}$ Mehdi Azad, ${ }^{3}$ \\ Sima Sadat Seyedjavadi, ${ }^{4}$ and Reza Mousavi ${ }^{5}$ \\ ${ }^{1}$ Department of Microbiology, School of Medicine, Shahid Beheshti University of Medical Science, Tehran 1985717443, Iran \\ ${ }^{2}$ WHO Collaborating Center for Reference and Research on Rabies, Pasteur Institute of Iran, Tehran 1316943551, Iran \\ ${ }^{3}$ Department of Medical Laboratory Sciences, School of Paramedicine, Qazvin University of Medical Sciences, Qazvin 1651135779, Iran \\ ${ }^{4}$ Department of Medical Mycology, Pasteur Institute of Iran, Tehran 1316943551, Iran \\ ${ }^{5}$ Department of Medical Laboratory Sciences, School of Paramedicine, Shahid Beheshti University of Medical Sciences, \\ Tehran 1985717443, Iran
}

Correspondence should be addressed to Sima Sadat Seyedjavadi; sima_seyedjavadi@yahoo.com

Received 7 May 2015; Revised 28 June 2015; Accepted 12 July 2015

Academic Editor: Athanassios Tsakris

Copyright (C) 2015 Mehdi Goudarzi et al. This is an open access article distributed under the Creative Commons Attribution License, which permits unrestricted use, distribution, and reproduction in any medium, provided the original work is properly cited.

\begin{abstract}
Objective. Aloe vera is an herbal medicinal plant with biological activities, such as antimicrobial, anticancer, anti-inflammatory, and antidiabetic ones, and immunomodulatory properties. The purpose of this study was investigation of in vitro antimicrobial activity of A. vera gel against multidrug-resistant (MDR) Pseudomonas aeruginosa isolated from patients with burn wound infections. Methods. During a 6-month study, 140 clinical isolates of $P$. aeruginosa were collected from patients admitted to the burn wards of a hospital in Tehran, Iran. Antimicrobial susceptibility test was carried out against the pathogens using the $A$. vera gel and antibiotics (imipenem, gentamicin, and ciprofloxacin). Results. The antibiogram revealed that 47 (33.6\%) of all isolates were MDR P. aeruginosa. The extract isolated from $A$. vera has antibacterial activity against all of isolates. Also, $42(89.4 \%)$ isolates were inhibited by $A$. vera gel extract at minimum inhibitory concentration (MIC) $\leq 200 \mu \mathrm{g} / \mathrm{mL}$. MIC value of $A$. vera gel for other isolates (10.6\%) was $800 \mu \mathrm{g} / \mathrm{mL}$. All of MDR P. aeruginosa strains were inhibited by A. vera at similar $\mathrm{MIC}_{50}$ and $\mathrm{MIC}_{90} 200 \mu \mathrm{g} / \mathrm{mL}$. Conclusion. Based on our results, $A$. vera gel at various concentrations can be used as an effective antibacterial agent in order to prevent wound infection caused by $P$. aeruginosa.
\end{abstract}

\section{Introduction}

Pseudomonas aeruginosa (P. aeruginosa) is increasingly recognized as one of the important nosocomial pathogens leading to severe infections especially in hospitalized patients in burn wards [1]. This opportunistic and highly resistant pathogen is responsible for a variety of nosocomial infections, including urinary or wound infections, bacteremia, endocarditis, and in some conditions death. P. aeruginosa infections in immunocompromised, debilitated patients, cystic fibrosis, and hospitalized burn patients are associated with increased rates of mortality and morbidity $[1,2]$.
The unselective and extensive use of antibiotics is highly considered as the major cause of invasive procedures. Accordingly, development of resistance mechanisms either intrinsic or acquired has promoted the rapid development of multiple resistances among $P$. aeruginosa isolates in the clinical settings [2]. The rapid increase of drug resistance in clinical isolates of $P$. aeruginosa is a growing concern among hospitalized patients $[3,4]$. During the past several decades, several different epidemiological studies indicated that multiple resistances among $P$. aeruginosa clinical isolates are increasing [5]. The widespread multidrug-resistant (MDR) $P$. aeruginosa strains not only lead to increased economic 
burden, but also can directly threaten the life of the patient. Ciprofloxacin, gentamycin, and imipenem are routinely used for treatment of the $P$. aeruginosa burn wound infections in Iran. Recently, overusing of imipenem in comparison with fluoroquinolones, beta lactams, and aminoglycoside, due to their resistance, demonstrated a risk of resistant to this antibiotic in $P$. aeruginosa isolated from burned patients [1]. Nowadays, multiple resistance mechanisms of $P$. aeruginosa isolates present serious therapeutic challenges for treatment [6]. Although antibiotics are routinely used for prevention of the $P$. aeruginosa burn wound infections, due to widespread MDR among $P$. aeruginosa strains leading to therapeutic failures, they are not recommended for regular prevention of burn wound infections associated with the bacteria $[1-3]$. The use of newer antibiotics, moist exposure therapy, mafenide acetate, antimicrobial peptides, and acticoat $\mathrm{AB}$ dressing (high-density polyethylene mesh coated with nanocrystalline silver) could be used for treatment of wound infected with MDR $P$. aeruginosa [1]. Generally, therapeutic strategies should be revised to control $P$. aeruginosa infections with emphasis on the use of extract and biologically active compounds isolated from the herbal plants. During the past several decades, many studies both in vivo and in vitro have demonstrated antibacterial activities of medicinal plants. According to estimates by World Health Organization (WHO), in developing countries, about $80 \%$ of the population mainly relies on traditional therapies and use of plant extracts as the main medicinal source to treat various infectious diseases $[7,8]$. In the recent years, extracts or oils of medicinal plants with antimicrobial and antiinflammatory effects have been used for treatment of many human infectious diseases. Aloe vera (A. vera) is one of these well-known medicinal plants [9]. A. vera is a cactus-like perennial, drought resistant, succulent plant belonging to the Liliaceae family, of which there are over 360 known species. The elongated and pointed leaves of plant contain two distinct products: yellow latex (exudate) and clear mucilaginous gel (A. vera gel). A. vera gel is revealed after removal of the thick outer cuticle [10]. The gel consists of $99.3 \%$ water and the remaining $0.7 \%$ containing a range of active compounds including polysaccharides, vitamins, amino acids, phenolic compounds, and organic acids [11]. Overall, more than 75 active ingredients have been identified from the inner gel [12]. A. vera was first used in the 1930 s to heal radiation burns [13]. To date, there are many reports of its beneficial properties in human, so that it is used for pharmaceutical, food, and cosmetic industries. A. vera gel has been used in gastrointestinal disorders, sunburn, and wounds since ancient times. Furthermore, various in vitro and in vivo studies on A. vera have demonstrated that it possesses several biological activities, such as anti-inflammatory, antioxidant, immune modulating, and cell growth stimulatory activity as well as antibacterial, antiviral, and antifungal properties [14].

Although antimicrobial properties of $A$. vera gel are primarily recognized, there is still little information on the uses of it and it needs to be more evaluated. The purpose of this study was to investigate the in vitro antimicrobial activity of $A$. vera gel against MDR P. aeruginosa isolated from burn wound infections.

\section{Materials and Methods}

2.1. Bacterial Strains. The present descriptive study was performed on burn cases that were hospitalized in a hospital in Tehran, Iran. A total of 140 clinical isolates of $P$. aeruginosa were collected from November 2014 to April 2015. Nonduplicate isolates were obtained from the burn wound specimens. The identification of isolates was carried out based on standard microbiological procedures such as Gram stain, catalase test, oxidase test, ornithine decarboxylase, arginine dihydrolase, growth at $42^{\circ} \mathrm{C}$, growth on Cetrimide agar medium (Liofilchem, Italy), O/F (Oxidation-Fermentation) test, and pigment production [16]. The confirmed strains isolated as $P$. aeruginosa were then stored at $-70^{\circ} \mathrm{C}$ in Tryptic Soy Broth (TSB) (Merck, Germany) containing 20\% (v/v) glycerol for further investigation.

2.2. Preparation of A. vera Gel. The plant of A. vera (leaves) was harvested from a local farm in the south Iran in January 2015. The plant was identified in the Research Center of Medicinal Plants. The collected mature and fresh leaves of $A$. vera were thoroughly washed with sterile distilled water to remove dirt and their thick epidermidis was then dissected longitudinally into pieces. The colourless parenchymatous tissue (aloe gel) was collected in a sterile container. One hundred grams of the gel was mixed in one liter of $2 \%$ dimethyl sulfoxide (DMSO) and kept at $4^{\circ} \mathrm{C}$, being used as a stock solution for Minimum Inhibitory Concentration (MIC) assay.

\subsection{Minimum Inhibitory Concentration (MIC) Assay}

2.3.1. MIC of Synthetic Antibiotics. The antimicrobial susceptibility test of isolates was determined by estimating MIC of the 3 antibiotics using microbroth dilution method according to the Clinical Laboratory and Standards Institute (CLSI, 2012) guidelines [15]. The MIC was defined as the lowest concentration of an antimicrobial agent that will inhibit the visible growth of the tested isolate. MIC $_{50}$ was defined as the MIC required to inhibit the growth of $50 \%$ of organisms and $\mathrm{MIC}_{90}$ was defined as the MIC required to inhibit the growth of $90 \%$ of organisms. The following antimicrobial agents were used in this study: imipenem, gentamicin, and ciprofloxacin (SigmaAldrich, St. Louis, Mo). The concentrations range of the used antimicrobial agents was, respectively, imipenem from 0.5 to $32 \mu \mathrm{g} / \mathrm{mL}$; gentamicin from 1 to 64 , and ciprofloxacin from 0.5 to $16 \mu \mathrm{g} / \mathrm{mL}$. The breakpoints for different antibiotics were as follows: imipenem $8 \mu \mathrm{g} / \mathrm{mL}$, gentamicin $16 \mu \mathrm{g} / \mathrm{mL}$, and ciprofloxacin $4 \mu \mathrm{g} / \mathrm{mL}$. P. aeruginosa ATCC 27853 was used as the control strain for antimicrobial susceptibility test.

2.3.2. MIC of Aloe vera Gel. In order to determine the MIC of $A$. vera gel against $P$. aeruginosa isolated from burned patients, broth microdilution method was carried out in 96well cell culture plates. In brief, the bacterial suspensions of the clinical isolates were obtained from overnight cultures. The turbidity of each bacterial suspension was adjusted equivalent to a number $0.5 \mathrm{McF}$ arland standard (approximately 1.0 $\times 10^{8} \mathrm{CFU} / \mathrm{mL}$ ). This suspension was further diluted 1:100 
TABLE 1: Summary of the antibacterial activities of A. vera gel and antimicrobial agents against clinical isolates of $P$. aeruginosa.

\begin{tabular}{|c|c|c|c|c|c|c|c|c|c|}
\hline \multirow{2}{*}{ Agent } & \multicolumn{3}{|c|}{ MIC $(\mu \mathrm{g} / \mathrm{mL})$} & \multicolumn{3}{|c|}{ Number (\%) of isolates } & \multicolumn{3}{|c|}{$\begin{array}{c}\text { MIC } \\
\text { interpretive } \\
\text { breakpoints }{ }^{\mathrm{a}}\end{array}$} \\
\hline & Range & $50 \%$ & $90 \%$ & S & I & $\mathrm{R}$ & S & I & $\mathrm{R}$ \\
\hline Aloe vera gel & $25-800$ & 200 & 200 & - & - & - & & & \\
\hline Ciprofloxacin & $0.5-16$ & 4 & 8 & $33(23.6)$ & $5(3.6)$ & $102(72.8)$ & $\leq 1$ & 2 & $\geq 4$ \\
\hline Gentamicin & $1-64$ & 8 & 32 & $61(43.6)$ & $5(3.6)$ & $74(52.8)$ & $\leq 4$ & 8 & $\geq 16$ \\
\hline Imipenem & $0.5-32$ & 4 & 16 & $70(50)$ & $4(2.9)$ & $66(47.1)$ & $\leq 2$ & 4 & $\geq 8$ \\
\hline
\end{tabular}

${ }^{a}$ MIC breakpoints applied were those recommended for P. aeruginosa by the Clinical and Laboratory Standards Institute (CLSI) [15].

$\left(10^{6} \mathrm{CFU} / \mathrm{mL}\right)$ in the broth media. Twofold dilutions of the A. vera gel stock solution were prepared in the appropriate broth culture media. Aliquots $(200 \mu \mathrm{L})$ of each dilution $(25$, $50,100,200,400$, and $800 \mu \mathrm{g} / \mathrm{mL}$ ) were dispensed in 96-well cell culture plates. One hundred microliters of each bacterial suspension was added to each well and incubated at $37^{\circ} \mathrm{C}$ overnight. Wells with DMSO (sterility control) and bacterial suspension (drug-free control) were also used as controls [17]. To estimate MIC of $A$. vera gel, the absorbance of each well was measured at $595 \mathrm{~nm}$. MIC level was defined as the lowest concentration at which no growth was observed.

2.4. Statistical Analysis. Statistical analysis was performed using SPSS software for Windows, version 17.0 (SPSS Inc., Chicago, IL).

\section{Results}

3.1. Antibacterial Activity of Antimicrobial Agents. During the 6-month study period, $140 \mathrm{P}$. aeruginosa isolates were recovered from hospitalized burns patients. Of the 140 isolates included in the study, 98 isolates $(70 \%)$ had been isolated from males and 42 isolates (30\%) had been isolated from females. The median age was 46.4 years with an age range from 5-month to 69-year old. The result of the antimicrobial susceptibility testing for $140 \mathrm{P}$. aeruginosa clinical isolates using microdilution method for three antibiotics tested revealed that resistance to ciprofloxacin was in 102 (72.8\%), to imipenem was in $66(47.1 \%)$, and to gentamicin was in $74(52.8 \%)$ isolates. Resistance rates varied among $P$. aeruginosa clinical isolates from $47.1 \%$ for imipenem to $72.8 \%$ for ciprofloxacin. MDR was defined as resistance to 2 or more antibiotics [4]. Forty-seven isolates (33.6\%) were characterized as the MDR $P$. aeruginosa strains.

3.2. Antibacterial Activity of Aloe vera Gel. The results obtained about antibacterial activities of $A$. vera gel showed that all of MDR $P$. aeruginosa strains except five of them were inhibited by $A$. vera gel extract at $\mathrm{MIC} \leq 400 \mu \mathrm{g} / \mathrm{mL}$. The MIC values of A. vera gel for the remaining five (10.6\%) isolates were $800 \mu \mathrm{g} / \mathrm{mL}$. Undiluted $A$. vera gel exhibited inhibitory effect on all of MDR isolates. None of the MDR isolates were sensitive to dilutions of $A$. vera gel less than $25 \mu \mathrm{g} / \mathrm{mL}$. In vitro susceptibility of the MDR $P$. aeruginosa strains to three antibiotics was performed and $A$. vera gel with the range of $\mathrm{MIC}_{50}$ and $\mathrm{MIC}_{90}$ are summarized in Table 1.

\section{Discussion}

In the our study, all of MDR $P$. aeruginosa strains (except five of them) were found to be sensitive to $A$. vera gel extract at $\mathrm{MIC} \leq 400 \mu \mathrm{g} / \mathrm{mL}$. Also, the data obtained in this study showed a good antibacterial activity of $A$. vera gel extract in different concentration against MDR $P$. aeruginosa isolated from burned patients despite many published reports in this regard. These controversial results could be attributed to difference in susceptibility testing method, difference in extraction process, stresses heat imposed on the gel, and the number of pharmacologically active compounds including anthraquinones, anthracene, anthranol, aloin, aloe mannan, aloetic acid, aloe emodin, aloeride, chrysophanic acid, resistanol, and saponin $[18,19]$.

Many medicinal plants as potential source of novel antimicrobial compounds, $A$. vera being the most important one, are widely used by large proportion of the Iranian population for treating burn wound infections [20-22]. These results regarding antibacterial activity are in conformity with earlier findings of Antonisamy et al. who found varied antibacterial antifungal activity of DMSO gel extracts of A. vera against five bacterial cultures of Bacillus subtilis, Salmonella typhi, Escherichia coli, and Staphylococcus aureus and three fungal cultures of Aspergillus fumigatus, Candida albicans, and Penicillium sps. The results showed that DMSO gel extracts of $A$. vera had highest degree of activity against the selected pathogens and the degree of inhibition varied depending upon the concentration of the extract [23-26]. Scientific evidences have proven that the constituents of gel and leaf are distinct from each other. Some of investigators believe that the gel is more active than the leaf, but one clear feature is that the gel and leaf can complement one another in their medicinal capabilities [27]. Surprisingly, there are contradictory studies about inhibitory effect of gel, leaf, and juice of $A$. vera. In 2010, Anderl et al. showed that both gel and leaf inhibited the growth of $S$. aureus isolated from wound infection while the gel has no effect on $P$. aeruginosa isolates [28].

Several studies exhibited higher level of antibacterial activity of $A$. vera gel against fungi strains [29]. Agarry et al. conducted a study to compare the antimicrobial activities of the gel and leaf of $A$. vera against $P$. aeruginosa, S. aureus, Microsporum canis, Trichophyton schoenleinii, T. mentagrophytes, and C. albicans. The results presented the significant antibacterial activity of both the gel and the leaf against 
S. aureus. The leaf possesses inhibitory effects on both $P$. aeruginosa and $C$. albicans while only the gel inhibited the growth of T. mentagrophytes [27]. Investigation of antimicrobial activities and MIC of $A$. vera gel and Aloe vera juice in the study of Kaithwas et al. in 2008 clearly demonstrated that $A$. vera juice has higher and broader spectrum of antimicrobial activity than $A$. vera gel [30]. This difference in activity of the juice as compared to gel could be attributed to presence of greater amount of the anthraquinones and phenolic antioxidants in the A. vera juice.

There are differences in the antimicrobial effects of various extracts of $A$. vera. Irshad et al. showed the $A$. vera extract of Methanol had the maximum antibacterial activity as compared to other solvents, ethanol, and distilled water [31]. The study of Ibrahim et al. in 2011, in order to investigate phytochemical analysis and antimicrobial evaluation of $A$. vera gel against some human and plant pathogens by disc diffusion method, was done with three different forms (ethanol, acetone, and aqueous extracts). The antibacterial and antifungal activity of the acetone extract was found to be more effective than ethanol and aqueous extracts [32]. Pandey and Mishra reported that there was no inhibitory effect of aqueous extract on the Gram negative bacteria and weak inhibitory effect on Gram positive bacteria [33]. Differences in the antimicrobial effects of various extracts of $A$. vera may be attributed to different solubility of various compounds found in A. vera, particularly, some solvents that have a specific antifungal or antimicrobial activity.

Although known ingredients in the A. vera leaf gel are obviously present in small mounts (about 1\%), they can be linked to work together and create synergistic effect so that the total effect is greater than what would be expected from the individual effect of each substance [34-36].

\section{Conclusion}

Our study supports the view that $A$. vera gel could be active against $P$. aeruginosa in wound infections at various concentrations and the use of it at optimum concentrations can help better therapy of many microbial diseases. Further investigations are required to identify bioactive components of $A$. vera gel and its effect on wide range of bacteria and fungus including the pathogenic strains. It is hoped that this study would lead to the development of aloe gel usage as a main medicinal source to treat various infectious diseases.

\section{Conflict of Interests}

The authors declare that there is no conflict of interests regarding the publication of this paper.

\section{Acknowledgment}

The authors appreciate the cooperation of the staff of Microbiology Department, Shahid Beheshti University of Medical Sciences.

\section{References}

[1] A. Japoni, S. Farshad, and A. Alborzi, "Pseudomonas aeruginosa: burn infection, treatment and antibacterial resistance,"
Iranian Red Crescent Medical Journal, vol. 11, no. 3, pp. 244-253, 2009.

[2] A. A. El Solh and A. Alhajhusain, "Update on the treatment of Pseudomonas aeruginosa pneumonia," Journal of Antimicrobial Chemotherapy, vol. 64, no. 2, Article ID dkp201, pp. 229-238, 2009.

[3] J. A. Driscoll, S. L. Brody, and M. H. Kollef, "The epidemiology, pathogenesis and treatment of Pseudomonas aeruginosa infections," Drugs, vol. 67, no. 3, pp. 351-368, 2007.

[4] J.-I. Sekiguchi, T. Asagi, T. Miyoshi-Akiyama et al., "Outbreaks of multidrug-resistant Pseudomonas aeruginosa in community hospitals in Japan," Journal of Clinical Microbiology, vol. 45, no. 3, pp. 979-989, 2007.

[5] O. Lomovskaya, M. S. Warren, A. Lee et al., "Identification and characterization of inhibitors of multidrug resistance efflux pumps in Pseudomonas aeruginosa: novel agents for combination therapy," Antimicrobial Agents and Chemotherapy, vol. 45, no. 1, pp. 105-116, 2001.

[6] J. Chen, Z. Su, Y. Liu et al., "Identification and characterization of class 1 integrons among Pseudomonas aeruginosa isolates from patients in Zhenjiang, China," International Journal of Infectious Diseases, vol. 13, no. 6, pp. 717-721, 2009.

[7] O. Akerele, "WHO guidelines for the assessment of herbal medicines," Fitoterapia, vol. 63, no. 2, pp. 99-104, 1992.

[8] K. Oluyemisi Folashade, E. Henry Omoregie, and A. Peter Ochogu, "Standardization of herbal medicines-a review," International Journal of Biodiversity and Conservation, vol. 4, no. 3, pp. 101-112, 2012.

[9] S. Thiruppathi, V. Ramasubramanian, T. Sivakumar, and V. Thirumalai Arasu, "Antimicrobial activity of Aloe vera (L.) Burm. f. against pathogenic microorganisms," The Journal of Biosciences Research, vol. 1, no. 4, pp. 251-258, 2010.

[10] A. Surjushe, R. Vasani, and D. Saple, "Aloe vera: a short review," Indian Journal of Dermatology, vol. 53, no. 4, pp. 163-166, 2008.

[11] F. Nejatzadeh-Barandozi, "Antibacterial activities and antioxidant capacity of Aloe vera," Organic and Medicinal Chemistry Letters, vol. 3, no. 5, pp. 1-8, 2013.

[12] S. A. Hashemi, S. A. Madani, and S. Abediankenari, "The review on properties of Aloe Vera in healing of cutaneous wounds," BioMed Research International, vol. 2015, Article ID 714216, 6 pages, 2015.

[13] T. Reynolds and A. C. Dweck, "Aloe vera leaf gel: a review update," Journal of Ethnopharmacology, vol. 68, no. 1-3, pp. 3-37, 1999.

[14] S. Satish, D. C. Mohana, M. P. Ranhavendra et al., "Antifungal activity of some plant extracts against important seed borne pathogens of Aspergillus sp.," International Journal of Agricultural Technology, vol. 3, no. 1, pp. 109-119, 2007.

[15] Clinical and Laboratory Standards Institute, Performance Standards for Antimicrobial Susceptibility Testing: Twenty Second Informational Supplement, M100-S20, CLSI, Wayne, Pa, USA, 2012.

[16] W. C. Winn and E. W. Koneman, Koneman's Color Atlas and Textbook of Diagnostic Microbiology, Lippincott Williams \& Wilkins, 2006.

[17] M. Fani and J. Kohanteb, "Inhibitory activity of Aloe vera gel on some clinically isolated cariogenic and periodontopathic bacteria," Journal of Oral Science, vol. 54, no. 1, pp. 15-21, 2012.

[18] O. Rosca-Casian, M. Parvu, L. Vlase, and M. Tamas, "Antifungal activity of Aloe vera leaves," Fitoterapia, vol. 78, no. 3, pp. 219222, 2007. 
[19] Y. Ni, D. Turner, K. M. Yates, and I. Tizard, "Isolation and characterization of structural components of Aloe vera L. leaf pulp," International Immunopharmacology, vol. 4, no. 14, pp. 1745-1755, 2004

[20] T. A. Hema, A. S. Arya, S. Suseelan, R. K. John Celestinal, and P. V. Divya, "Antimicrobial activity of five South Indian medicinal plants against clinical pathogens," International Journal of Pharma and Bio Sciences, vol. 4, no. 1, pp. 70-80, 2013.

[21] G. S. Prashar P, V. Koul, and S. Sehgal, "In vitro antimicrobial activity of ethanolic extract of Aloe vera against some bacterial and fungal species," Advanced Biotechnology, vol. 11, no. 3, pp. 32-33, 2011

[22] S. Alemdar and S. Agaoglu, "Investigation of in vitro antimicrobial activity of Aloe vera juice," Journal of Animal and Veterinary Advances, vol. 8, no. 1, pp. 99-102, 2009.

[23] M. Chinedu Stanley, O. Emmanuel Ifeanyi, and O. Godson Eziokwu, "Antimicrobial effects of Aloe vera on some human pathogens," International Journal of Current Microbiology and Applied Sciences, vol. 3, no. 3, pp. 1022-1028, 2014.

[24] V. G. Manikandan and M. H. Muhammad Ilyas, "Analysis of phytochemical constituents and antibacterial activities of Aloe vera L. against some selected pathogens," International Journal of Biology, Pharmacy and Allied Sciences, vol. 3, no. 1, pp. 56-62, 2014.

[25] S. R. Shilpakala, J. Prathiba, and R. Malathi, "Susceptibilities of Escherichia coli and Staphylococcus aureus to Aloe barbadensis," European Review for Medical and Pharmacological Sciences, vol. 13, no. 6, pp. 461-464, 2009.

[26] J. M. A. Antonisamy, N. Beaulah, R. Laju et al., "Anti-bacterial and antigungal activity of Aloe vera gel extract," International Journal of Biomedical and Advance Research, vol. 3, no. 3, pp. 184-187, 2012.

[27] O. O. Agarry, M. T. Olaleye, and C. O. Bello-Michael, "Comparative antimicrobial activities of aloe vera gel and leaf," African Journal of Biotechnology, vol. 4, no. 12, pp. 1413-1414, 2005.

[28] J. N. Anderl, M. J. Franklin, and P. S. Stewart, "Role of antibiotic penetration limitation in Klebsiella pneumoniae biofilm resistance to ampicillin and ciprofloxacin," Antimicrobial Agents and Chemotherapy, vol. 44, no. 7, pp. 1818-1824, 2010.

[29] S. Manipal, F. Shireen, and D. Prabu, "Anti-fungal activity of Aloe vera: In vitro stud," SRM Journal of Research in Dental Sciences, vol. 6, no. 2, pp. 92-95, 2015.

[30] G. Kaithwas, A. Kumar, H. Pandey et al., "Investigation of comparative antimicrobial activity of Aloe vera gel and juice," Pharmacologyonline, vol. 1, pp. 239-243, 2008.

[31] S. Irshad, M. Butt, and H. Younus, "In-vitro antibacterial activity of Aloe barbadensis Miller (Aloe vera)," International Research Journal of Pharmaceuticals, vol. 1, pp. 60-65, 2011.

[32] M. Ibrahim, M. Srinivas, and M. Lakshmi Narasu, "Phytochemical analysis and antimicrobial evaluation of Aloe vera gel against some human and plant pathogens," Asian Journal of Current Chemistry, vol. 1, no. 1, pp. 1-11, 2011.

[33] R. Pandey and A. Mishra, "Antibacterial activities of crude extract of Aloe barbadensis to clinically isolated bacterial pathogens," Applied Biochemistry and Biotechnology, vol. 160, no. 5, pp. 1356-1361, 2010.

[34] S. Subramanian, D. S. Kumar, P. Arulselvan, and G. P. Senthilkumar, "In vitro antibacterial and antifungal activities of ethanolic extract of Aloe vera leaf gel," Journal of Plant Sciences, vol. 1, no. 4, pp. 348-355, 2006.
[35] M. H. Radha and N. P. Laxmipriya, "Evaluation of biological properties and clinical effectiveness of Aloe vera: a systematic review," Journal of Traditional and Complementary Medicine, vol. 5, no. 1, pp. 21-26, 2015.

[36] L. Cellini, S. Di Bartolomeo, E. Di Campli, S. Genovese, M. Locatelli, and M. Di Giulio, "In vitro activity of aloe vera inner gel against Helicobacter pylori strains," Letters in Applied Microbiology, vol. 59, no. 1, pp. 43-48, 2014. 


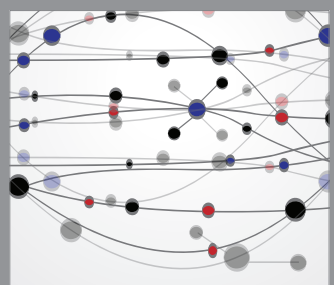

The Scientific World Journal
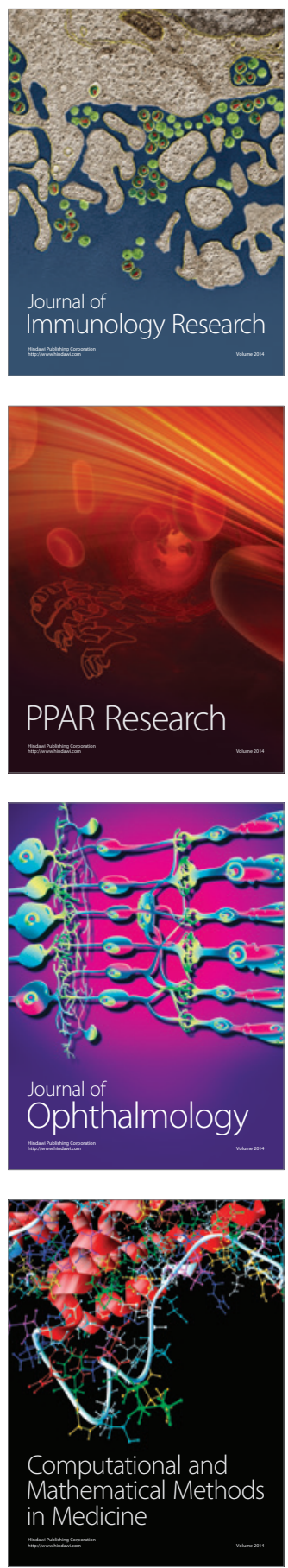

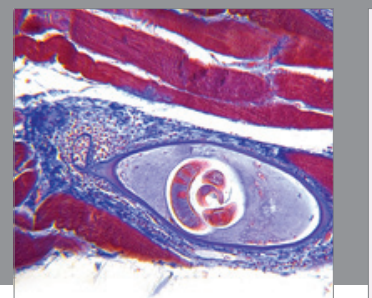

Gastroenterology

Research and Practice
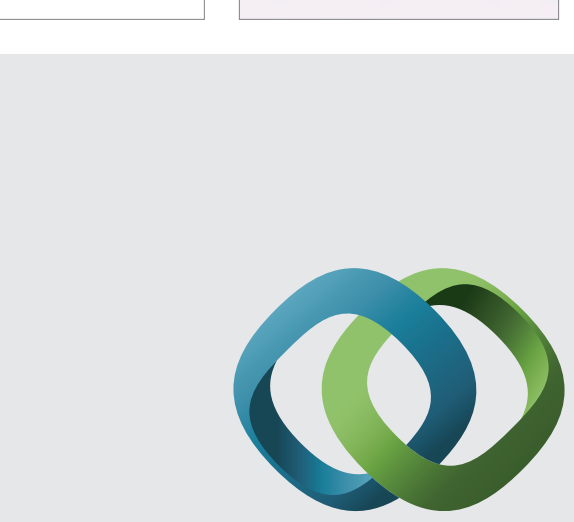

\section{Hindawi}

Submit your manuscripts at

http://www.hindawi.com
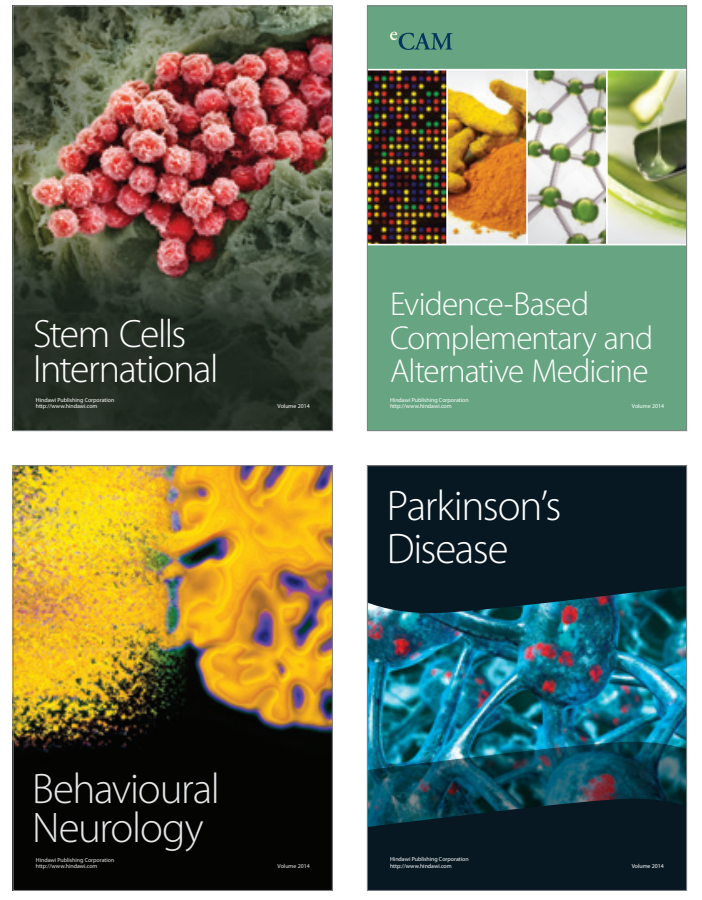
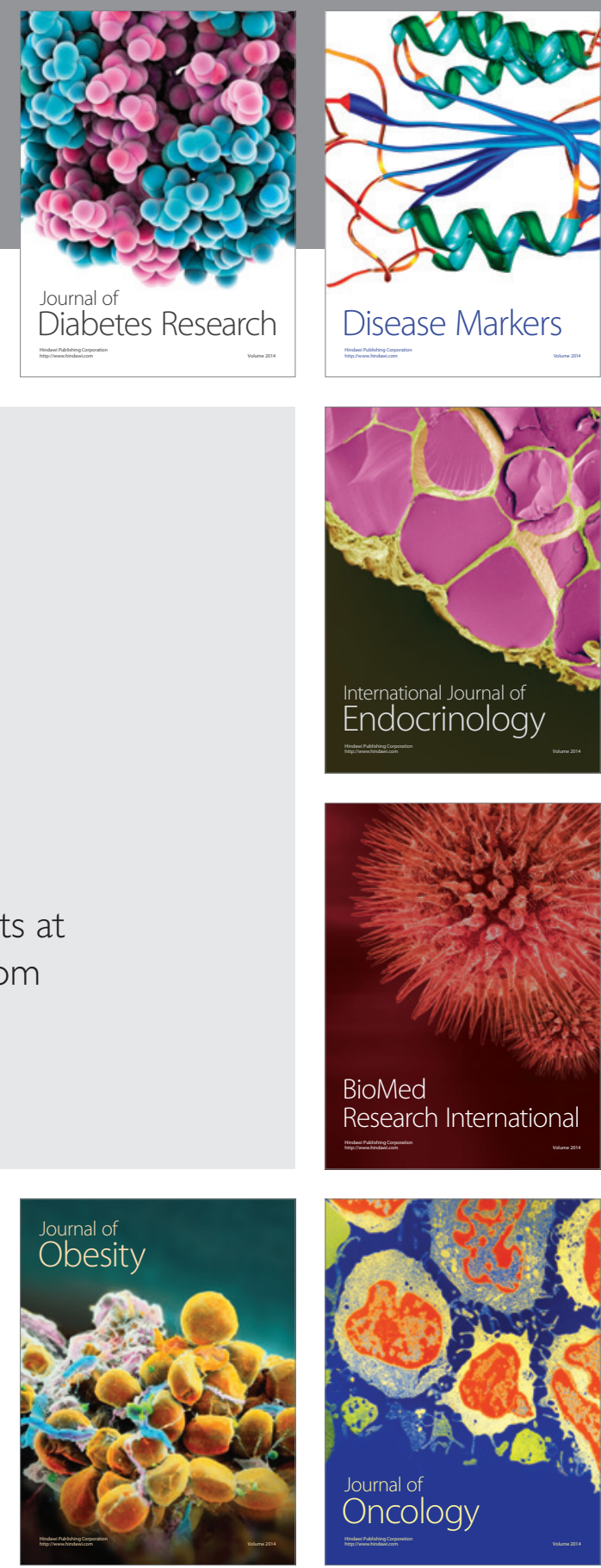

Disease Markers
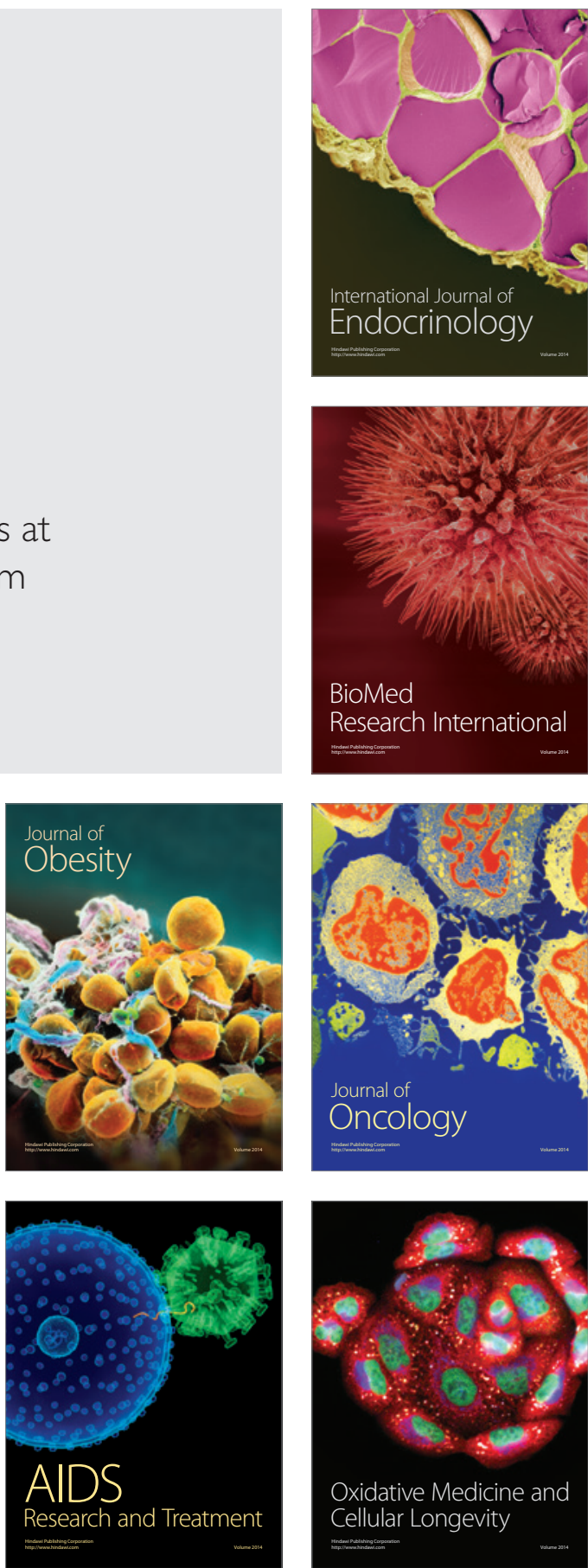